Simple Lateral Suboccipital Approach and Modification for Vertebral Artery Aneurysms : A Study of 52 Cases Over 10 Years

\title{
Tjahjadi, Mardjono
}

2017-12

Tjahjadi , M , Jahromi , B R , Serrone , J , Nurminen , V , Choque-Velasquez , J , Kivisaari , R , Lehto , H , Niemelä , M \& Hernesniemi , J 2017 , ' Simple Lateral Suboccipital Approach and Modification for Vertebral Artery Aneurysms : A Study of 52 Cases Over 10 Years ', World Neurosurgery , vol. 108 , pp. 336-346 . https://doi.org/10.1016/j.wneu.2017.09.014

http://hdl.handle.net/10138/298144

https://doi.org/10.1016/j.wneu.2017.09.014

publishedVersion

Downloaded from Helda, University of Helsinki institutional repository.

This is an electronic reprint of the original article.

This reprint may differ from the original in pagination and typographic detail.

Please cite the original version. 


\section{Simple Lateral Suboccipital Approach and Modification for Vertebral Artery Aneurysms: A Study of 52 Cases Over 10 Years \\ Mardjono Tjahjadi, Behnam Rezai Jahromi, Joseph Serrone, Ville Nurminen, Joham Choque-Velasquez, Riku Kivisaari, Hanna Lehto, Mika Niemelä, Juha Hernesniemi}

INTRODUCTION: Complex skull base approaches are frequently used to treat intracranial vertebral artery (VA) and proximal posterior inferior cerebellar artery (PICA) aneurysms. These complex procedures are associated with higher risk of neurovascular injury. Hence, a less-invasive surgical approach is needed to improve the efficacy and safety of treatment.

METHODS: A retrospective analysis was conducted on clinical and radiologic data from surgeries in which simple lateral suboccipital and "lateral-enough" approaches were used to clip VA aneurysms in the Department of Neurosurgery at Helsinki University Central Hospital from 2000 to 2009 .

RESULTS: Fifty-two VA or PICA aneurysms were treated using the simple lateral suboccipital approach. Sixteen patients $(31 \%)$ presented with an unruptured aneurysm, 21 patients $(40 \%)$ with World Federation of Neurosurgical Societies (WFNS) grade $1-3$, and 15 patients (29\%) with World Federation of Neurosurgical Societies grade 4-5. The aneurysms were saccular in 48 cases $(92 \%)$, dissecting in 3 cases $(6 \%)$, and fusiform in 1 case $(2 \%)$. The most common aneurysm location was the VA-PICA junction (81\%). The mean final modified Rankin Scale score was 2, and in unruptured cases, all patients had favorable clinical outcomes. The main causes of unfavorable outcome were poor preoperative clinical grade $(P=0.002)$, preoperative intraventricular hemorrhage $(P=0.008)$, postoperative hydrocephalus $(P=0.003)$, brain infarction $(P=0.005)$, and postoperative pneumonia $(P<0.001)$.

CONCLUSIONS: We describe a 10-year experience using a simple lateral suboccipital approach and its modification by the senior author (J.H.) to treat VA and proximal PICA aneurysms. Unfavorable outcome was related to the poor preoperative clinical grade, preoperative intraventricular hemorrhage, and postoperative pneumonia.

\section{INTRODUCTION}

V ertebral artery (VA) aneurysms account for approximately $3 \%$ of all intracranial aneurysms and $10 \%-15 \%$ of aneurysms in the vertebrobasilar system. ${ }^{\mathrm{I}-5}$ Treatment of VA aneurysms can be difficult because of the relationship of the VA with the brainstem, tortuosity, and proximity to lower cranial nerves. The lateral suboccipital approach was classically used to treat these aneurysms. ${ }^{6-9}$

Because of the long working distance and narrow working corridor, more extensive skull base procedures have been used (e.g., far-lateral, transcondylar, paracondylar, juxtacondylar, supracondylar, transjugular, or extreme lateral approach). ${ }^{\mathrm{IO}-26}$ The goal of these skull base approaches is to remove the bony anatomy lateral to the foramen magnum (i.e., occipital condyle and jugular tubercle), allowing for a larger working corridor. ${ }^{16,27,28}$ However, more extensive skull base approaches are associated with

\section{Key words \\ - Aneurysm clipping \\ - Lateral suboccipital approach \\ - Vertebral artery aneurysm}

Abbreviations and Acronyms
CSF: Cerebrospinal fluid
CT: Computed tomography
IAR: Intraoperative aneurysm rupture
IVH: Intraventricular hemorrhage
LCNP: Lower cranial nerve palsy
LOS: Length of stay
mRS: Modified Rankin Scale
PICA: Posterior inferior cerebellar artery

\section{Abbreviations and Acronyms}

IAR: Intraoperative aneurysm rupture

IVH: Intraventricular hemorrhage

LOS: Length of stay

PICA: Posterior inferior cerebellar artery
VA: Vertebral artery

WFNS: World Federation of Neurosurgical Societies

Department of Neurosurgery, University of Helsinki and Helsinki University Hospital, Helsinki, Finland

To whom correspondence should be addressed: Mardjono Tjahjadi, M.D.

[E-mail:mardjonotjahjadi@gmail.com; joy_mardjono@yahoo.com]

Citation: World Neurosurg. (2017) 108:336-346.

https://doi.org/10.1016/j.wneu.2017.09.014

Journal homepage: www.WORLDNEUROSURGERY.org

Available online: www.sciencedirect.com

1878-8750/\$ - see front matter (c) 2017 Elsevier Inc. All rights reserved. 
increased surgical time and carry potential complications of neurovascular injury and craniocervical instability. ${ }^{27}$

The improvement of neuroanesthetic techniques along with the advancement in microsurgical equipment may reduce the need of these extensive surgical approaches. In this study, we assess the efficacy of a simple lateral suboccipital approach and its modification used by the senior author (J.H.) to treat VA aneurysms.

\section{METHODS}

A retrospective analysis was conducted on clinical and radiologic data from surgeries in which simple lateral suboccipital and "lateral-enough" approaches were used to clip VA aneurysms in the Department of Neurosurgery at Helsinki University Central Hospital from 2000 to 2009. The preoperative and postoperative radiologic examination and analyses were mostly based on computed tomography (CT) and CT angiography. Digital subtraction angiography was used if there was uncertainty in initial diagnosis or in evaluation of the operative result. This study was approved by the research ethics committee of Helsinki University Central Hospital.

\section{Patient Data}

We reviewed 6or patients with posterior circulation aneurysms. In these patients, microsurgery was performed in $42 \mathrm{I}$ aneurysms, endovascular therapy in 66 aneurysms, and conservative management in II4 aneurysms. The lateral suboccipital approach was performed on 52 aneurysms in 51 patients.

\section{Clinical Data}

Preoperative clinical condition for ruptured aneurysms was assessed using the World Federation of Neurosurgical Societies (WFNS) score (good, I-3; poor, 4-5). The outcome after surgery was assessed using the modified Rankin Scale (mRS) score at discharge and at final follow-up. Outcomes were classified as favorable ( $\mathrm{mRS}$ score $\mathrm{o}-3$ ), unfavorable ( $\mathrm{mRS}$ score $4-5$ ), or death (mRS score 6).

\section{Radiologic Measurement}

Preoperative and postoperative radiologic data for the study were obtained from CT angiography and digital subtraction angiography. Radiologic images were analyzed both in 2 dimensions and in 3 dimensions using the GE Centricity RA 600 software (GE Medical Systems, Milwaukee, Wisconsin, USA) and the IMPAX software version 5.3 (Agfa, Mortsel, Belgium). The aneurysm characteristics for statistical analysis included I) aneurysm dome size, 2) neck size, and 3) postoperative angiographic occlusion. Aneurysm dome size was categorized as very small $(<3 \mathrm{~mm})$, small $(3-6 \mathrm{~mm})$, medium $(7-\mathrm{I} 3 \mathrm{~mm})$, large ( $14-24 \mathrm{~mm})$, or giant $(\geq 25 \mathrm{~mm})$. The degree of occlusion was categorized as complete occlusion (100\%), near-complete/neck remnant $(>90 \%)$, partial occlusion $(80 \%-90 \%)$, incomplete occlusion $(<80 \%)$, and treatment failure (unable to clip aneurysm).

\section{Statistical Analysis}

The continuous data are expressed as means with ranges in parentheses and tested with the Student $t$ test and analysis of variance. Categorical variables are presented as percentages and are analyzed using a $\chi^{2}$ test. A P value less than 0.05 was considered significant. Statistical analysis was performed using SPSS software for Macintosh (version 22.o [IBM Corp., Armonk, New York, USA]).

\section{Operative Technique and Methods}

Patient Positioning. For the lateral suboccipital approach, ${ }^{29}$ the patient is placed in the lateral park bench position with the head elevated $20 \mathrm{~cm}$ above the heart level. The upper body is rotated slightly $\left(5^{\circ}-10^{\circ}\right)$ anteriorly and the upper shoulder is heavily retracted caudally and posteriorly. The head is positioned I) flexed slightly; 2) tilted contralaterally; and 3) slightly rotated toward the floor, with the mastoid tip becoming the highest point. A lumbar drain is placed to release $50 \mathrm{~mL}$ of cerebrospinal fluid (CSF).

Skin Incision and Craniotomy. A vertical linear skin incision is placed $2 \mathrm{~cm}$ behind the mastoid process centered over the transverse sigmoid junction (Figure 1). A curved self-retaining

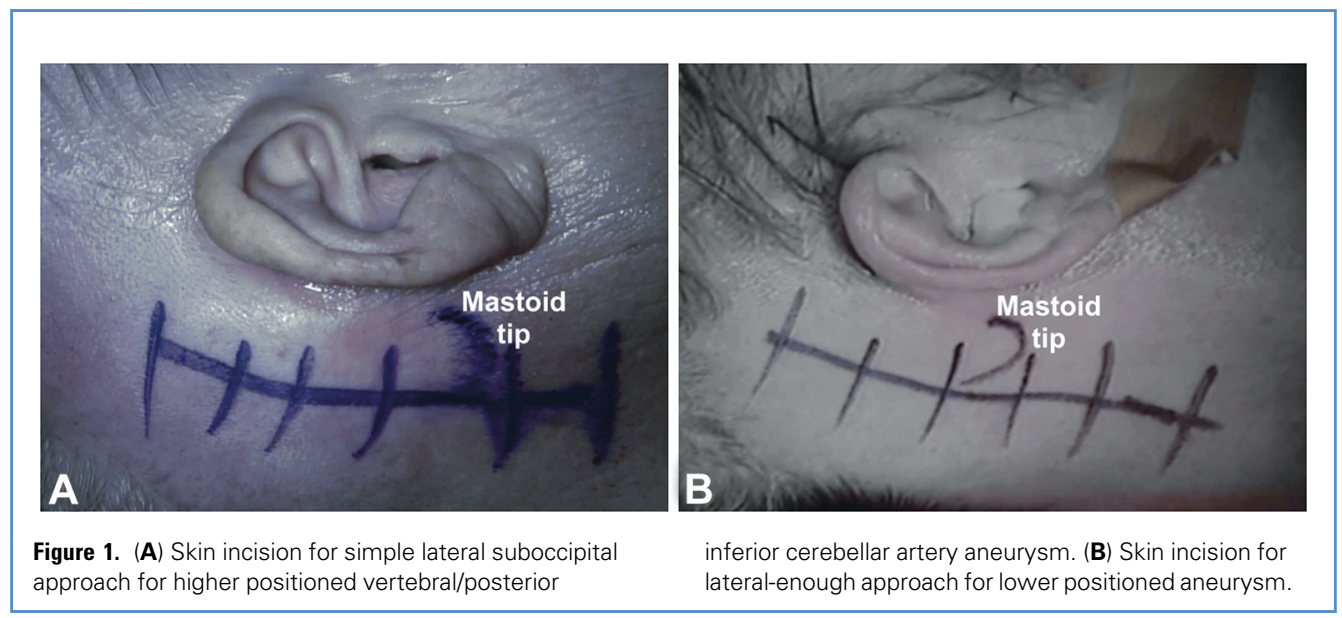


retractor is placed from the cranial side of the incision. The subcutaneous fat and muscles are split along the linear incision with electrocautery to the occipital bone. Subperiosteal dissection is continued to expose the occipital bone.

One burr hole is placed at the posterior aspect of the exposed occipital bone. An osteotome with a footplate is used to create a $2-\mathrm{cm}$ to $3-\mathrm{cm}$ bone flap. The mastoid bone is drilled to expose the posterior border of the sigmoid sinus. If the VA aneurysm is located low ( $<$ IO $\mathrm{mm}$ above the foramen magnum), the craniotomy is extended medial and inferiorly to open the lateral foramen magnum (lateral-enough approach) (Figures 1 and 2).

Aneurysm Identification, Dissection, and Occlusion. After dural opening, the cisterna magna is opened to release more CSF. The cerebellomedullary space is subsequently entered anteriorly and dissection is continued into the lateral medullary space. The cranial part of the inth cranial nerve and proximal intradural VA are encountered first. Following the course of the VA distally, the ninth and tenth cranial nerves as well as the anterior and lateral medullary segments of the posterior inferior cerebellar artery (PICA) are seen. A good viewing angle, sharp dissection, and fine movement under high magnification are mandatory to perform safe aneurysm dissection (Figure 3). If the jugular tubercle obstructs the surgical view, rotating the patient's head contralaterally and elevating the table to look under the jugular tubercle often solves this problem.

After proximal and distal sides of the parent artery are identified, a straight temporary clip is placed on the VA proximal to the aneurysm. A pilot clip is placed on the aneurysm parallel to the distal VA direction. The aneurysm dome is dissected to confirm a good clip position across the neck with preservation of the PICA.
The temporary clip is removed and the aneurysm and vessels are evaluated with Doppler ultrasonography and indocyanine green video angiography. A papaverin-soaked Surgicel (Ethicon) ball is then applied to alleviate any surgically induced vasospasm. The surgical wound was closed under high magnification. ${ }^{30}$

\section{RESULTS}

From 2000 to 2009, the senior author (J.H.) performed the lateral suboccipital approach and modified lateral-enough approach to operate on $5 \mathrm{I}$ patients with 52 cases of VA and proximal PICA aneurysms.

\section{General Characteristics of the Patients}

The clinical characteristics in this series are shown in Table 1. Sixteen patients $(3 \mathrm{I} \%)$ presented with an unruptured aneurysm, 2I patients $(40 \%)$ were good grade, and 15 patients $(29 \%)$ were poor grade. The female/male ratio was 2.6:I. The mean age was 58.7 years (range, 32-80 years). One patient had 2 aneurysms on opposite sides clipped at different times.

\section{General Aneurysm Characteristics}

Aneurysm Characteristics. The aneurysms were saccular in 48 cases ( $92 \%)$, dissecting in 3 cases $(6 \%)$, and fusiform in I case $(2 \%)$. The mean aneurysm dome size was $6.8 \mathrm{~mm}$ (range, 2-2I mm). The mean aneurysm neck size for saccular and dissecting aneurysms was $4 \mathrm{~mm}$. The small and medium-sized groups comprised most of our cases, accounting for 28 (54\%) and 13 (25\%) cases, respectively.

Aneurysm Location. The most common aneurysm location was the VA-PICA junction $(8 \mathrm{I} \%)$. The remaining aneurysm locations in

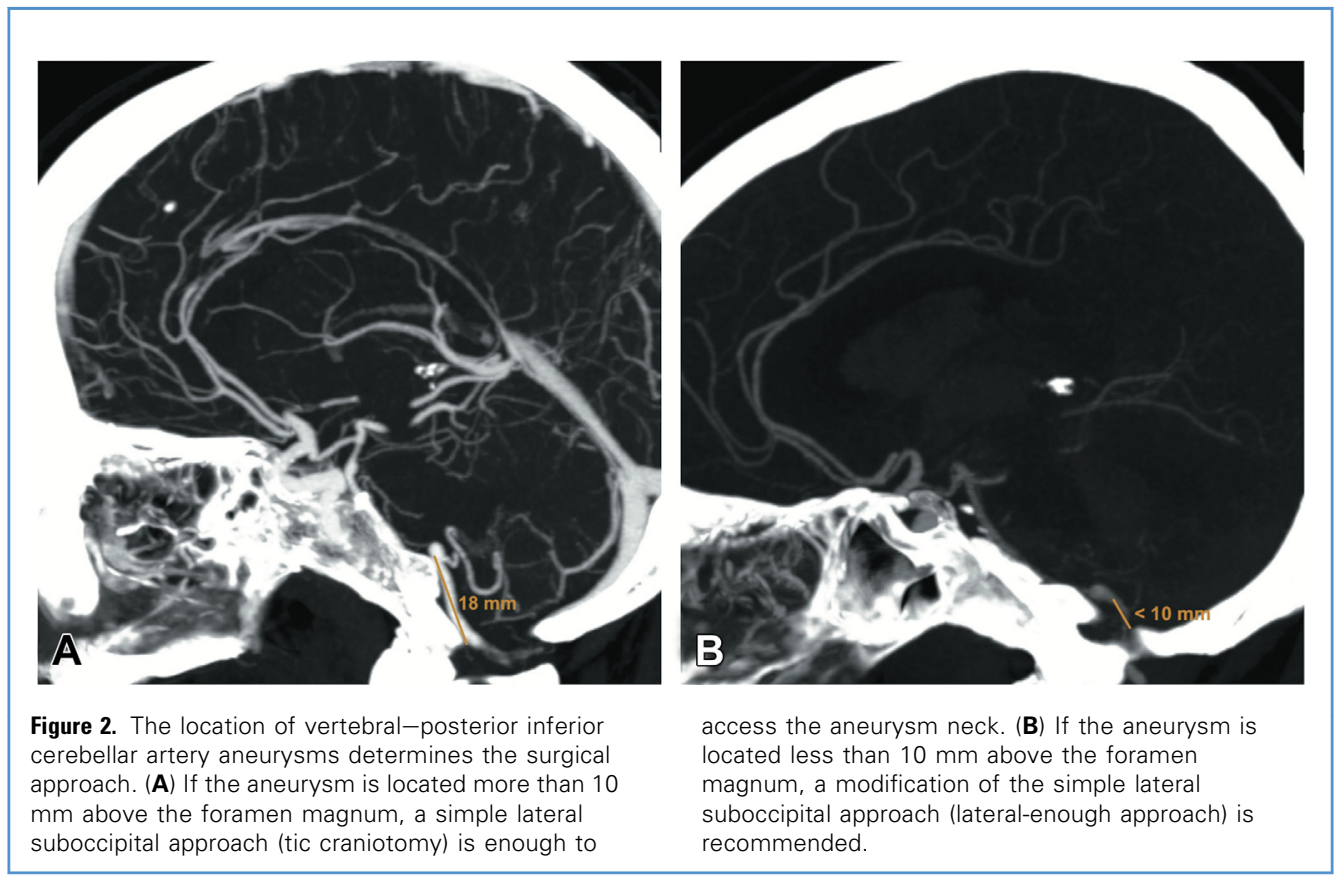



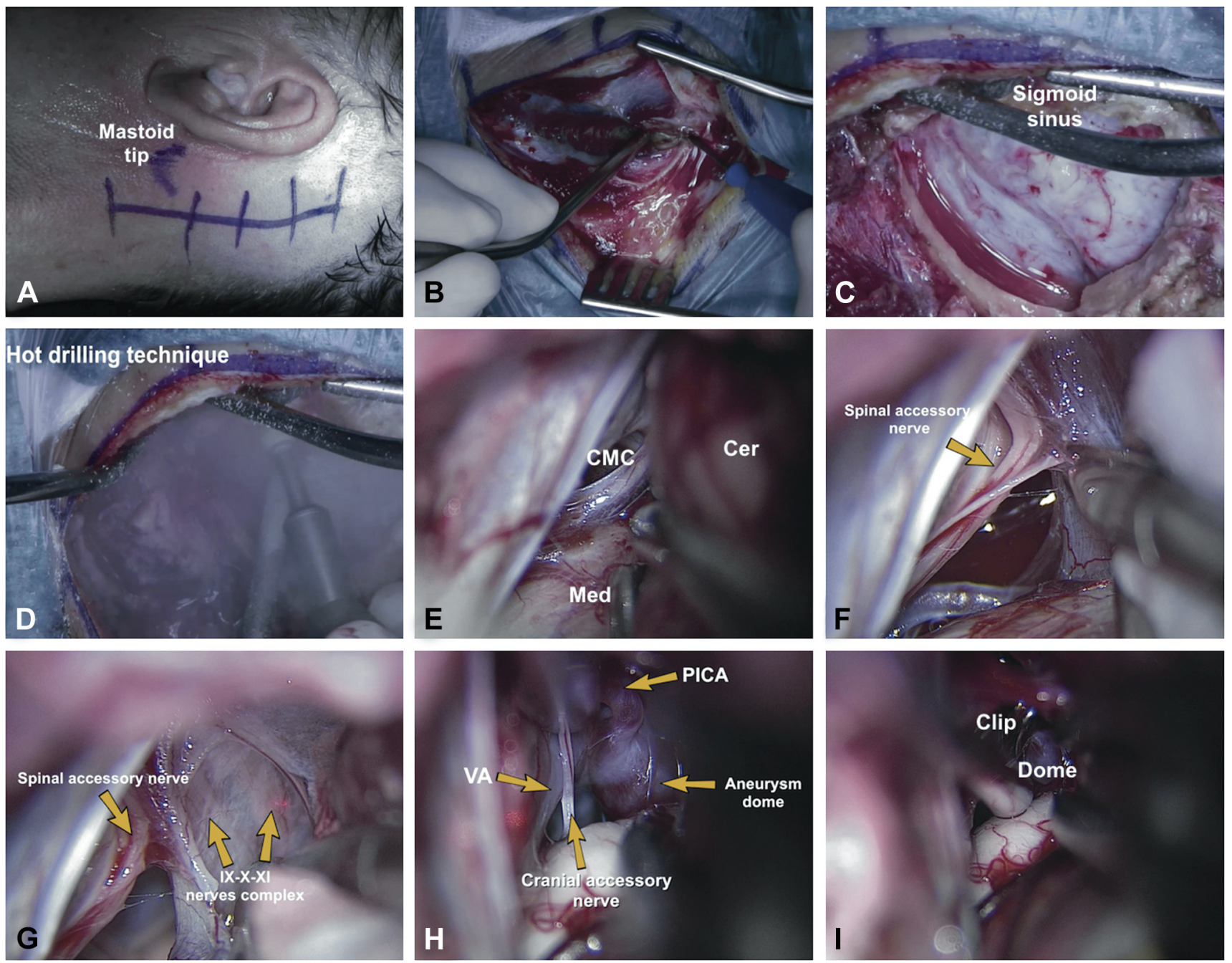

Figure 3. Steps of the simple lateral suboccipital approach to clip a vertebral-posterior inferior cerebellar artery (PICA) junction aneurysm. The senior author (J.H.) usually performs the whole procedure starting from skin incision under microscope. (A) Skin incision marking. (B) Soft tissue dissection, which is meticulously performed using monopolar cauterization under high magnification. (C) The exposure of a small craniotomy flap

(usually a $2-\mathrm{cm}$ to $3-\mathrm{cm}$ bone flap is enough). (D) Hot drilling technique to control the bleeding from the bone and to increase the retrosigmoid

exposure. (E) Opening the cerebellomedullary cistern $(\mathrm{CMC})$ to release the cerebrospinal fluid and to gain access to proximal control. (F) Sharp dissection of the arachnoid bands around the neurovascular structures. (G) Identification of cranial nerves 9-11 complex; the aneurysm was located just medial and anterior to the complex. (H) Vertebral-posterior inferior cerebellar artery junction aneurysm was nicely exposed and accessed from a space between the spinal accessory nerve and cranial nerves 9-11 complex. (I) Definitive clip application to the aneurysm neck, preserving a good flow of vertebral and posterior inferior cerebellar artery. Cer, cerebellum, Med, medulla oblongata. decreasing order of frequency were the vertebral trunk, proximal PICA, and vertebrobasilar junction (Table 1). Nineteen cases were right sided $(37 \%)$ and 33 were left sided $(63 \%)$.

\section{Clinical Outcome}

Patients' outcomes were evaluated with an average follow-up of 3.5 months (o-I8 months). The mean discharge mRS score was 3.2 and the mean final mRS score was 2. A favorable clinical outcome in the final follow-up was found in $3^{8}$ patients $(73 \%)$. The rate of favorable outcome in the unruptured group was Ioo\%. Preoperative clinical grade was significantly related to the final clinical outcome $(P=0.002)$. All $\mathrm{r} 6$ unruptured patients had a favorable outcome with mean final mRS score of 0.94. In ruptured cases, good grade and poor grade had favorable outcomes of $7 \mathrm{I} \%$ and $47 \%$, respectively. Other factors associated with unfavorable clinical outcome were preoperative intraventricular hemorrhage (IVH) $(\mathrm{P}=0.008)$, postoperative hydrocephalus $(\mathrm{P}=0.003)$, brain infarction $(\mathrm{P}=0.005)$, and postoperative pneumonia $(\mathrm{P}<\mathrm{o.ooI}$ ) (Table 2$)$.

IVH and Postoperative Hydrocephalus. Thirty-two patients presented with IVH. Ventriculostomy was performed in $\mathrm{I} 3$ patients $(4 \mathrm{I} \%)$ 
Table 1. Clinical Characteristic of 52 Patients in Our Series

\begin{tabular}{|c|c|c|c|}
\hline Description & Unruptured $(n=16)$ & Good Grade $(n=21)$ & Poor Grade $(n=15)$ \\
\hline Age, years ( $n=52)$, mean (range) & $55.6(34-77)$ & $62.1(42-80)$ & $57.3(32-77)$ \\
\hline \multicolumn{4}{|l|}{ Gender $(n=52)$} \\
\hline Male & $3(19)$ & $6(29)$ & $5(33)$ \\
\hline Female & $13(81)$ & $15(71)$ & $10(67)$ \\
\hline \multicolumn{4}{|l|}{ Aneurysm morphology } \\
\hline Saccular $(n=48)$ & $15(94)$ & $20(95)$ & $13(87)$ \\
\hline Fusiform $(\mathrm{n}=1)$ & $1(6)$ & $0(0)$ & $0(0)$ \\
\hline Dissecting $(n=3)$ & $0(0)$ & $1(5)$ & $2(13)$ \\
\hline Mean aneurysm size, mm (range) & $7.3(2-21)$ & $6.1(2$ 17) & $7.2(2-17)$ \\
\hline \multicolumn{4}{|l|}{ Aneurysm location } \\
\hline Vertebral artery-PICA & $13(81)$ & $16(76)$ & $13(87)$ \\
\hline Proximal PICA & $1(6)$ & $1(5)$ & $0(0)$ \\
\hline Vertebral trunk & $2(13)$ & $3(14)$ & $2(13)$ \\
\hline Vertebrobasilar junction & $0(0)$ & $1(5)$ & $0(0)$ \\
\hline Operative time (skin-to-skin) (minutes) & $89.9(30-169)$ & $96.3(40-189)$ & $99.7(50-179)$ \\
\hline Hospital length of stay (days) & $12(4-62)$ & $17(5-46)$ & $21(2-59)$ \\
\hline \multicolumn{4}{|l|}{ Immediate occlusion grade $(n=44)$} \\
\hline Complete & $11(92)$ & $17(89)$ & $12(92)$ \\
\hline Neck remnant (near complete) & $1(8)$ & $2(11)$ & $0(0)$ \\
\hline Incomplete & $0(0)$ & $0(0)$ & $1(8)$ \\
\hline \multicolumn{4}{|c|}{ Final occlusion grade (mean follow-up, 3.5 months) $(n=44)$} \\
\hline Complete & $11(92)$ & $17(89)$ & $12(92)$ \\
\hline Neck remnant (near complete) & $1(8)$ & $2(11)$ & $0(0)$ \\
\hline Incomplete & $0(0)$ & $0(0)$ & $1(8)$ \\
\hline
\end{tabular}

with IVH and 6 patients with ventriculostomy needed shunting. Postoperative hydrocephalus was found in 15 of 36 ruptured patients $(42 \%)$ and all had preoperative IVH. Preoperative IVH showed was strongly associated with unfavorable outcomes $(4 \mathrm{I} \%$ vs. $5 \%$; $=0.008$; Table 2).

\section{Perioperative Complications}

Postoperative Pneumonia. Postoperative pneumonia occurred in 23 patients $(44 \%)$ and $48 \%$ of patients with pneumonia had an unfavorable outcome at discharge mRS score $(\mathrm{P}<$ o.oor) (Table 3$)$. Poor preoperative clinical grade $(\mathrm{P}=0.009)$, IVH $(\mathrm{P}=0.026)$, and postoperative hydrocephalus $(\mathrm{P}=0.004)$ were related to the incidence of postoperative pneumonia (Table 4). In subgroup analysis of good-grade patients, postoperative pneumonia was associated with unfavorable outcomes $(\mathrm{P}=0.029)$. Lower cranial nerve palsy (LCNP) was not found as a significant factor in the development of pneumonia $(\mathrm{P}=0.465)$.
Vasospasm, Brain Infarction, and Parent Artery Occlusion Times. Symptomatic vasospasm was found in 5 patients (го). All cases were treated with medical management (i.e., no endovascular treatment) and 4 patients recovered with favorable outcome. Brain infarction occurred in Io patients ( $19 \%)$. Six patients $(60 \%)$ with infarction had an unfavorable outcome. No decompressive craniectomy as a result of cerebellar infarction was necessary. The only factor associated with brain infarction was a longer duration of parent artery occlusion (mean occlusion times of 17.6 minutes vs. 5.5 minutes; $\mathrm{P}=0.006)$. Overall, parent artery occlusion times did not predict clinical outcome (favorable outcomes 5.9 minutes vs. unfavorable outcomes II.6 minutes; $P=0.137)$. However, poor-grade patients with favorable outcomes had a lower mean occlusion time (2.5 minutes) compared with poor-grade patients with unfavorable outcomes ( 13.5 minutes; $\mathrm{P}=0 . \mathrm{OII})$.

Postoperative LCNP. A total of 20 patients (39\%) had LCNP postoperatively. Of these 20 patients, 5 had LCNP preoperatively and 15 
Table 2. Factors Related to Patient's Outcome

\begin{tabular}{|c|c|c|c|c|}
\hline Description & Favorable & Unfavorable & Dead & $P$ Value \\
\hline Age, years ( $n=52)$, mean (range) & $56.6(32-79)$ & $64.8(49-80)$ & $62(47-77)$ & $0.112^{*}$ \\
\hline \multicolumn{5}{|l|}{ Gender } \\
\hline Male & $7(50)$ & $6(43)$ & $1(7)$ & $0.075+$ \\
\hline Female & $31(82)$ & $6(16)$ & $1(2)$ & \\
\hline \multicolumn{5}{|c|}{ Preoperative World Federation of Neurosurgical Societies grade $(n=52)$} \\
\hline Unruptured $(n=16)$ & $16(100)$ & $0(0)$ & $0(0)$ & $0.002 \dagger$ \\
\hline Good grade $(1-3)(n=21)$ & $15(71)$ & $6(29)$ & $0(0)$ & \\
\hline Poor grade $(4-5)(n=15)$ & $7(47)$ & $6(40)$ & $2(13)$ & \\
\hline \multicolumn{5}{|c|}{ Preoperative intraventricular hemorrhage $(n=52)$} \\
\hline Yes & $19(59)$ & $11(34)$ & $2(6)$ & $0.008+$ \\
\hline No & $19(95)$ & $1(5)$ & $0(0)$ & \\
\hline \multicolumn{5}{|l|}{ Postoperative HCP ( $n=52$ ) } \\
\hline Yes & $7(44)$ & $7(44)$ & $2(22)$ & $0.003+$ \\
\hline No & $31(86)$ & $5(14)$ & $0(0)$ & \\
\hline \multicolumn{5}{|c|}{ Postoperative lower cranial nerve palsy ( $n=52$ ) } \\
\hline No & $23(72)$ & $7(22)$ & $2(6)$ & $0.245 \dagger$ \\
\hline Transient & $10(91)$ & $1(9)$ & $0(0)$ & \\
\hline Permanent & $5(56)$ & $4(44)$ & $0(0)$ & \\
\hline \multicolumn{5}{|l|}{ Postoperative pneumonia $(n=52)$} \\
\hline Yes & $12(52)$ & $11(48)$ & $0(0)$ & $<0.001 \dagger$ \\
\hline No & $26(90)$ & $1(3)$ & $2(7)$ & \\
\hline \multicolumn{5}{|l|}{ Brain infarction } \\
\hline Yes & $4(40)$ & $4(40)$ & $2(20)$ & $0.005 \dagger$ \\
\hline No & $34(83)$ & $7(17)$ & 0 & \\
\hline \multicolumn{5}{|l|}{ Aneurysm related } \\
\hline Mean aneurysm size, $\mathrm{mm}$ (range) & $6.2(2-21)$ & $7.8(3-17)$ & $12(7-17)$ & $0.137^{*}$ \\
\hline \multicolumn{5}{|c|}{$\begin{array}{l}\text { Values are number (\%) except where indicated otherwise. } \\
H C P \text {, hydrocephalus. } \\
{ }^{*} \text { Analysis of variance. } \\
\dagger \chi^{2} \text {. }\end{array}$} \\
\hline
\end{tabular}

(29\%) developed LCNP postoperatively. Of the I5 patients with newly developed postoperative LCNP, 9 had complete resolution of symptoms (mean follow-up, 3.5 months). Six patients (II.5\%) had permanent LCNP, 4 of whom had mild symptoms and 2 of whom had severe symptoms of dysphagia and needed tracheostomy. The only factor that determined LCNP was aneurysm dome size (Table 5). Permanent LCNP, transient LCNP, and no LCNP were found in mean aneurysm dome sizes of $10.6 \mathrm{~mm}, 6.7 \mathrm{~mm}$, and $5.8 \mathrm{~mm}$, respectively $(\mathrm{P}=\mathrm{o.02 \textrm {I }})$ (Table 5).

Surgical Time, Intraoperative Aneurysm Rupture, and Other Complications. Mean surgical time was 95 minutes (range, 30-I89 minutes). Intraoperative aneurysm rupture (IAR) occurred in I4 patients $(27 \%)$ and mostly occurred in ruptured cases $(93 \%)$. In the I4 patients experiencing IAR, $5(36 \%)$ had an unfavorable outcome. Unfavorable outcomes in IAR cases (36\%) was not statically higher than in cases without IAR (I8\%, P = 0.297). No postoperative CSF leak or wound infection was reported in our series. More information on perioperative complications is available in Table 3.

\section{Endovascular to Microsurgery Switching}

In this series, we found 4 patients $(8 \%)$ who initially underwent attempted endovascular embolization before requiring microsurgery. The causes of endovascular treatment failure were access failure in I patient, incomplete occlusion $(<80 \%)$ in I patient, and intraprocedural aneurysm rupture in 2 patients. After 
Table 3. Perioperative Complications

\section{Description}

Unruptured, n (\%)

Brain infarction $(\mathrm{n}=10)$

Postoperative lower cranial nerve palsy $(n=15)$

$$
\text { Temporary }
$$

Permanent

Vasospasm

Wound infection

Cerebrospinal fluid leakage

Postoperative pneumonia $(n=23)$

1 (7)

$2(20)$

$3(33)$

2 (33)

$0(0)$

$0(0)$

$0(0)$

$3(13)$
Good Grade, n (\%)

$9(64)$

$3(30)$

$5(50)$

2 (22)

4 (44)

2 (33)

2 (33)

$2(40)$

$3(60)$

$0(0)$

$0(0)$

$0(0)$

$0(0)$

9 (39)

$11(48)$

Table 4. Causes and Impacts of Postoperative Pneumonia

\section{Variables}

Age, years $(n=52)$, mean (range)

Gender $(n=52)$

Female

Male

Preoperative World Federation of Neurosurgical Societies grade $(n=52)$

Unruptured

Good grade

Poor grade

Preoperative intraventricular hemorrhage $(n=52)$

Yes

No

Postoperative lower cranial nerve palsy $(n=52$

No

Transient

Permanent

Postoperative HCP $(n=52)$

Yes

No

Discharge modified Rankin Scale score $(n=52)$

Favorable outcome

Unfavorable outcome

Death

Hospital length of stay (days) $(n=52)$, mean (range)

Values are number (\%) except where indicated otherwise

$\mathrm{HCP}$, hydrocephalus.

${ }^{*}$ Student $t$ test.

$\dagger \chi^{2}$.
Pneumonia

No Pneumonia

$P$ Value

$59.7(32-80)$

$57.9(34-79)$

$0.591^{*}$

$14(61)$

9 (39)

$24(83)$

5 (17)

9 (39)

$3(13)$

$5(17)$

$13(45)$

12 (41)

11 (48)

4 (14)

\begin{tabular}{|r|r|}
\hline $18(78)$ & $14(48)$ \\
\hline $5(22)$ & $15(52)$ \\
\hline
\end{tabular}

$12(52)$

$6(26)$

$20(69)$

$5(17)$

$5(22)$

4 (14)

12 (75)

$11(31)$

$0.004 \dagger$

$4(25)$

25 (69)

$\begin{array}{cc}12(52) & 26(90) \\ 11(48) & 1(3) \\ 0(0) & 2(7)\end{array}$

$23.7(5-62)$

$11.3(2-28)$

$<0.001^{*}$ 
Table 5. Lower Cranial Nerves Palsy Incidence in Our Series

\begin{tabular}{|c|c|c|c|c|}
\hline Variables & No Lower Cranial Nerve Palsy & Transient & Permanent & $P$ Value \\
\hline Age (years), mean (range) & $57.5(32-79)$ & $56.2(34-76)$ & $66.1(49-80)$ & $0.125^{*}$ \\
\hline \multicolumn{5}{|l|}{ Sex } \\
\hline Male & $8(25)$ & $3(27)$ & $3(33)$ & $0.886 \dagger$ \\
\hline Female & $24(75)$ & $8(73)$ & $6(67)$ & \\
\hline \multicolumn{5}{|c|}{ World Federation of Neurosurgical Societies score } \\
\hline Unruptured & $11(34)$ & $3(27)$ & $2(22)$ & $0.921 \dagger$ \\
\hline Good grade & $13(41)$ & $4(36)$ & $4(44)$ & \\
\hline Poor grade & $8(25)$ & $4(36)$ & $4(33)$ & \\
\hline Aneurysm size, mm, mean (range) & $5.8(2-17)$ & $6.7(2-21)$ & $10.6(5-20)$ & $0.021^{*}$ \\
\hline Temporary occlusion, minutes, mean (range) & $8.4(0-64)$ & $4.5(0-11)$ & $8.9(0-46)$ & $0.638^{*}$ \\
\hline $\begin{array}{l}\text { Values are number (\%) except where indicated oth } \\
\text { *Analysis of variance. } \\
\dagger \chi^{2} \text {. }\end{array}$ & & & & \\
\hline
\end{tabular}

microsurgical clipping, 3 patients had complete occlusion and I patient had near-complete aneurysm occlusion. Clinical outcome was favorable in 3 patients and unfavorable in I patient. No clipped patients were referred to the endovascular service for further treatment.

\section{Hospital Length of Stay}

The mean length of stay (LOS) in unruptured, good-grade, and poor-grade cases was 12 days (range, 4-62 days), I7 days (range, 5-46 days), and 2I days (range, 2-59 days), respectively $(\mathrm{P}=$ o.I4I). Two factors related to prolonged hospitalization were preoperative IVH and postoperative pneumonia. Patients with and without preoperative IVH had a mean LOS of I9 and 12 days, respectively $(\mathrm{P}=0.046)$. The LOS in patients with and without postoperative pneumonia were 24 and II days, respectively $(\mathrm{P}<$ o.ooI $)$.

\section{Aneurysm Radiographic Outcome}

In 44 cases with postoperative imaging, a complete occlusion and near-complete/small neck remnant was achieved in 40 aneurysms $(9 \mathrm{r} \%)$ and 3 aneurysms $(7 \%)$, respectively. In the final angiography follow-up, all but I patient had a stable occlusion grade. Regarding aneurysm size, the very small, small, and mediumsized aneurysms had complete occlusion or a near-complete/ small neck remnant rate of $100 \%, 96 \%$, and $100 \%$, respectively. In large aneurysms, the complete occlusion or near-complete/ small neck remnant occlusion rate was $80 \%$. Only I patient in our series had an incomplete occlusion $(<80 \%)$ after microsurgical clipping.

\section{DISCUSSION}

Microsurgical clipping for VA and PICA aneurysms has technical challenges because of their deep location and their proximity to vital neurovascular structures. The far-lateral approach and its modifications provide wider working spaces and are most commonly used. However, the potential for morbidity related to the progressive drilling of the bony structures, such as occipitocervical instability, CSF leak, and VA injury, is higher with these approaches, which negatively influences the postoperative outcome. ${ }^{21,3 \mathrm{I}-36}$

Several series of microsurgical treatment for VA and PICA aneurysms have been reported. Favorable outcomes in these series range between $65 \%$ and $9 \mathrm{I}^{\mathrm{O}} \%{ }^{\mathrm{I}, 37-42}$ A recent institutional experience reported the use of a similar simplified lateral suboccipital approach to VA and PICA aneurysms in 26 patients with good outcome (mRS score $\mathrm{o}-3$ ) in 22 patients $(85 \%) .{ }^{\mathrm{I}}$ Another recent report of a modified far-lateral approach without condyle resection in 56 patients with VA and PICA aneurysms reported that this less-invasive approach also offers excellent surgical exposure, with complete occlusion rate achieved in all patients and good clinical outcome (Glasgow Outcome Scale score 4-5) achieved in 52 patients $(93 \%) .{ }^{43}$ Our series comprises 52 consecutive cases with a comparable favorable outcome of $100 \%$ in unruptured and $71 \%$ in good-grade patients.

\section{Lateral Enough Is Enough}

In the present series, we showed the classic lateral suboccipital approach with or without foramen magnum bone drilling. Lehto ${ }^{44}$ reported that a simple lateral suboccipital or tic craniotomy can be used if the location of the aneurysm is at least Io $\mathrm{mm}$ above the foramen magnum. However, for low-lying aneurysms $(<$ Io $\mathrm{mm}$ above the foramen magnum), a more inferolateral approach is considered. We extend our craniotomy inferiorly to open the foramen magnum lip and term this a lateral-enough approach. Drilling some part of the upper rim of Ci or part of the occipital condyle is possibly needed if the aneurysm location is more toward the midline, but this is rare. We coagulate the venous plexus, but we never mobilize the VA, because it is not necessary.

The main obstacle in microsurgery of VA or proximal PICA aneurysms is not the bony structures of the skull base but the 
neurovascular structures that obscure the aneurysm neck. Therefore, careful study of three-dimensional preoperative imaging is important and the keys to increase the surgical exposure should be directed toward neuroanesthesiology techniques to maintain a slack brain and using high microscopic magnification during surgery. ${ }^{45}$ In our experience, the bony structure that commonly obstructed the surgical visualization is the jugular tubercle. The trick used by our senior author (J.H.) to overcome this situation and minimize the risk of neurovascular injury is to drill partially the jugular tubercle and to raise the table high so that the surgeon visualizes the surgical field under the bony roof.

\section{IAR, Temporary Clipping Strategy, and Brain Infarction}

Generally, IAR has been shown to increase the risk of unfavorable outcome in well-powered microsurgical series. ${ }^{46-50}$ Our series found that cases of IAR had a statistically insignificant increased likelihood of unfavorable outcome. It is possible that our series was underpowered to show worse outcomes in IAR cases.

Temporary clip placement in aneurysm surgery is a fundamental strategy to reduce or even prevent the risk of devastating IAR and facilitates clip placement. The maximum time limit for placing the temporary clip is still controversial, but several studies reported that occlusion times of $\mathrm{I}_{4}-20$ minutes are safe..$^{\mathrm{I}-54}$ Schick et al. found that a mean temporary occlusion time of more than 8 minutes increased the risk of neurologic deficit to $80.9 \%$, whereas occlusion time below 8 minutes led to neurologic deficits in only $30.7 \%$ of cases. ${ }^{55}$ For posterior circulation aneurysms, occlusion times of $\mathrm{I}_{4}-\mathrm{I} 5$ minutes are considered a safe cutoff point. ${ }^{54,56}$ If the occlusion time is suspected to be more than 15 minutes, Eftekhar and Morgan ${ }^{56}$ suggest using thiopentone to create temporary burst suppression before temporary clip application.

From our series, we suggest a cutoff point to safely occlude the parent artery of 6 minutes. We compared cases with temporary occlusion time of 6 minutes or less and those with more than 6 minutes and found a significant difference in the incidence of brain infarction $(\mathrm{P}=0.003)$ and in final clinical outcome $(\mathrm{P}=0.043)$. Our findings also suggest that in patients with WFNS grade $4-5$, temporary occlusion of the parent artery should be performed even more cautiously. Applying a distal temporary clip may be difficult because it is often obstructed by the aneurysm. In the case of no access to distal temporary clipping, we usually used combined proximal temporary clipping and adenosine injection during aneurysm dissection and/or aneurysm clipping.

LCNP. LCNP has long been known as a frequent complication of microsurgical treatment for VA and PICA aneurysms. The incidence of LCNP ranges from $20 \%$ to $60 \%$. Al-khayat et al. ${ }^{57}$ reported that temporary parent artery occlusion was the most significant cause of postoperative LCNP. In the present series, we did not find a strong relationship of LCNP with the duration parent artery occlusion. We only found a correlation of aneurysm size to the incidence of LCNP. This finding offers evidence that manipulation of cranial nerves during surgery is the main factor contributing to postoperative LCNP.

\section{Endovascular and Microsurgery Perspective}

Endovascular therapy is also used to treat VA and PICA aneurysms, with varying results. The favorable clinical outcome of some larger series of endovascular procedures treating VA and PICA aneurysms was reported between $49 \%$ and $83 \% .^{58-65}$ The complete aneurysm occlusion in endovascular treatment was reported between $65 \%$ and $83 \%{ }^{60,63,65-67}$ The endovascular retreatment rate for VA and PICA aneurysms was reported around 20\%-30\%. ${ }^{58,68}$ A recent comparative study between clipping and coiling in 102 patients with VA and PICA aneurysm ${ }^{69}$ did not show any significant difference in the patients' clinical outcomes. Our results compare favorably with these endovascular results. The role of microneurosurgery in VA and proximal PICA aneurysm cases is still essential because many patients worldwide do not have access to endovascular treatment.

\section{Limitations}

The aim of our study was to describe our experience in using a simple lateral suboccipital approach to treat VA and proximal PICA aneurysm. Given that VA and proximal PICA aneurysms occur uncommonly, even at high-volume centers, we included cases of both ruptured and unruptured aneurysms to power the statistical analysis. Because of the many pathologic mechanisms of subarachnoid hemorrhage, there are worse outcomes in ruptured versus unruptured cases unrelated to the surgical approach. The limitations of a retrospective design are also present in this series.

\section{CONCLUSIONS}

We have described a Io-year experience using a simple lateral suboccipital approach by the senior author (J.H.) to treat VA and proximal PICA aneurysms. Aneurysms located Io $\mathrm{mm}$ above the foramen magnum can be safely reached with a simple lateral suboccipital approach, whereas aneurysms located below this point can be accessed with a lateral suboccipital approach and opening of the foramen magnum (lateral-enough approach). The overall clinical and radiologic results in our series are comparable to other surgical and endovascular series. In the present series, unfavorable outcome was related to poor preoperative WFNS grade, preoperative IVH, and postoperative pneumonia.

\section{REFERENCES}

I. Drake CG, Peerless SJ, Hernesniemi JA. Surgery of Vertebrobasilar Aneurysm London, Ontario Experience on 1767 Patients. New York: Springer-Verlag; I996.

2. Helmut Bertalanffy LB, Heinze S, Tirakotai W, Sure U. Surgical management of aneurysms of the vertebral and posterior inferior cerebellar artery complex. In: Quiñones-Hinojosa A, ed. Schmidek \&
Sweet Operative Neurosurgical Techniques : Indications, Methods, and Results. 6th ed Vol. I. Philadelphia, PA: Elsevier/Saunders; 20I2:I. online resource (2 volumes).

3. Hudgins RJ, Day AL, Quisling RG, Rhoton AL Jr, Sypert GW, Garcia-Bengochea F. Aneurysms of the posterior inferior cerebellar artery. A clinical and anatomical analysis. J Neurosurg. I983;58:38I-387.
4. Peerless SJ, Hernesniemi JA, Gutman FB, Drake CG. Early surgery for ruptured vertebrobasilar aneurysms. J Neurosurg. I994;80:643-649.

5. Rice BJ, Peerless SJ, Drake CG. Surgical treatment of unruptured aneurysms of the posterior circulation. J Neurosurg. I990;73:165-173.

6. Dimsdale H, Logue V. Ruptured posterior fossa aneurysms and their surgical treatment. J Neurol Neurosurg Psychiatry. I959;22:202-217. 
7. Jamieson KG. Aneurysms of the vertebrobasilar system; surgical intervention in I9 cases. J Neurosurg. I964;2I:78I-797.

8. Karasawa J, Kikuchi H, Furuse S, Sakaki T, Yoshida Y. Surgery of vertebral aneurysms at the origin of PICA (author's transl). No Shinkei Geka. I976;4:II57-II63 [in Japanese].

9. Norlen G, Paly SN. Aneurysms of the vertebral artery. Report of two operative cases. J Neurosurg. I960;17:830-835.

Io. Heros RC. Lateral suboccipital approach for vertebral and vertebrobasilar artery lesions. J Neurosurg. I986;64:559-562.

II. Day JD, Fukushima T, Giannotta SL. Cranial base approaches to posterior circulation aneurysms. J Neurosurg. I997;87:544-554.

I2. Rhoton AL Jr. The far-lateral approach and its transcondylar, supracondylar, and paracondylar extensions. Neurosurgery. 2000;47(3 suppl): Si95-209.

I3. Bertalanffy H, Seeger W. The dorsolateral, suboccipital, transcondylar approach to the lower clivus and anterior portion of the craniocervical junction. Neurosurgery. I99I;29:815-82I.

I4. Gilsbach JM, Sure U, Mann W. The supracondylar approach to the jugular tubercle and hypoglossal canal. Surg Neurol. I998;50:563-570.

I5. Kawashima M, Tanriover N, Rhoton AL Jr, Ulm AJ, Matsushima T. Comparison of the far lateral and extreme lateral variants of the atlantooccipital transarticular approach to anterior extradural lesions of the craniovertebral junction. Neurosurgery. 2003;53:662-674 [discussion: 674$675]$.

I6. Lanzino G, Paolini S, Spetzler RF. Far-lateral approach to the craniocervical junction. Neurosurgery. 2005;57(4 suppl):367-371 [discussion: 36737I].

17. Matsushima T, Matsukado K, Natori Y, Inamura T, Hitotsumatsu T, Fukui M. Surgery on a saccular vertebral artery-posterior inferior cerebellar artery aneurysm via the transcondylar fossa (supracondylar transjugular tubercle) approach or the transcondylar approach: surgical results and indications for using two different lateral skull base approaches. J Neurosurg. 200I;95:268-274.

I8. Nanda A, Konar S, Bir SC, Maiti TK, Ambekar S. Modified far lateral approach for posterior circulation aneurysms: an institutional experience. World Neurosurg. 2016;94:398-407.

I9. Nanda A, Vincent DA, Vannemreddy PS, Baskaya MK, Chanda A. Far-lateral approach to intradural lesions of the foramen magnum without resection of the occipital condyle. J Neurosurg. 2002;96:302-309.

20. Salas E, Sekhar LN, Zival IM, Caputy AJ, Wright DC. Variations of the extreme-lateral craniocervical approach: anatomical study and clinical analysis of 69 patients. J Neurosurg. I999;90(2 suppl):206-2I9.

2I. Spektor S, Anderson GJ, McMenomey SO, Horgan MA, Kellogg JX, Delashaw JB Jr.
Quantitative description of the far-lateral trans condylar transtubercular approach to the foramen magnum and clivus. J Neurosurg. 2000;92:824-83I.

22. Wen HT, Rhoton AL Jr, Katsuta T, de Oliveira E. Microsurgical anatomy of the transcondylar supracondylar, and paracondylar extensions of the far-lateral approach. J Neurosurg. I997;87:555-585.

23. Krayenbuhl N, Guerrero C, Krisht AF. Technical strategies to approach aneurysms of the vertebral and posterior inferior cerebellar arteries. Neurosurg Focus. 2005;I9:E4.

24. Sanai N, Tarapore P, Lee AC, Lawton MT. The current role of microsurgery for posterior circulation aneurysms: a selective approach in the endovascular era. Neurosurgery. 2008;62:1236-I249 [discussion: I249-I253].

25. Babu RP, Sekhar LN, Wright DC. Extreme lateral transcondylar approach: technical improvements and lessons learned. J Neurosurg. 1994;81:49-59.

26. Hammon WM, Kempe LG. The posterior fossa approach to aneurysms of the vertebral and basilar arteries. J Neurosurg. I972;37:339-347.

27. Elhammady MS, Peterson EC, Heros RC, Morcos JJ. Far lateral approach and transcondylar and supracondylar extensions for aneuryms of the vertebrobasilar junction. In: QuiñonesHinojosa A, ed. Schmidek \& Sweet Operative Neurosurgical Techniques: Indications, Methods, and Results. 6th ed Vol. I. Philadelphia, PA: Elsevier; 20I2: 95I-957.

28. Wu A, Zabramski JM, Jittapiromsak P, Wallace RC, Spetzler RF, Preul MC. Quantitative analysis of variants of the far-lateral approach: condylar fossa and transcondylar exposures. Neurosurgery. 20I0;66(6 suppl operative):IgI-Ig8 [discussion: 198].

29. Lehecka M, Laakso A, Hernesniemi J. Common approaches. In: Lehecka M, Laakso A, Hernesniemi J, eds. Helsinki Microneurosurgery. Vol. I. Helsinki: Druckerei Hohl GmbH \& Co. KG; 20II:I60-169.

30. Kivelev J, Hernesniemi J. Four-fold benefit of wound closure under high magnification. Surg Neurol Int. 2013;4:II5.

3r. Bejjani GK, Sekhar LN, Riedel CJ. Occipitocervical fusion following the extreme lateral transcondylar approach. Surg Neurol. 2000;54:I09-II5 [discussion: II5-II6].

32. Kshettry VR, Healy AT, Colbrunn R, Beckler DT, Benzel EC, Recinos PF. Biomechanical evaluation of the craniovertebral junction after unilateral joint-sparing condylectomy: implications for the far lateral approach revisited. J Neurosurg. 20I6:I-8.

33. Rohde V, Schaller C, Hassler W. The extreme lateral transcondylar approach to aneurysms of the vertebrobasilar junction, the vertebral artery, and the posterior inferior cerebellar artery. Skull Base Surg. I994;4:177-180.

34. Sen CN, Sekhar LN. An extreme lateral approach to intradural lesions of the cervical spine and foramen magnum. Neurosurgery. I990;27:197-204.
35. Shin H, Barrenechea IJ, Lesser J, Sen C, Perin NI Occipitocervical fusion after resection of craniovertebral junction tumors. J Neurosurg Spine. 2006; 4:I37-I44.

36. Vishteh AG, Crawford NR, Melton MS Spetzler RF, Sonntag VK, Dickman CA. Stability of the craniovertebral junction after unilatera occipital condyle resection: a biomechanical study. J Neurosurg. I999;90(I suppl):9I-98.

37. Andoh T, Shirakami S, Nakashima T, Nishimura Y, Sakai N, Yamada H, et al. Clinical analysis of a series of vertebral aneurysm cases. Neurosurgery. I992;31:987-993 [discussion: 993].

38. D'Ambrosio AL, Kreiter KT, Bush CA, Sciacca RR, Mayer SA, Solomon RA, et al. Far lateral suboccipital approach for the treatment of proximal posteroinferior cerebellar artery aneurysms: surgical results and long-term outcome. Neurosurgery. 2004;55:39-50 [discussion: 50-54].

39. Horowitz M, Kopitnik T, Landreneau F, Krummerman J, Batjer HH, Thomas G, et al. Posteroinferior cerebellar artery aneurysms: surgical results for 38 patients. Neurosurgery. I998;43: IO26-I032.

40. Liew D, Ng PY, Ng I. Surgical management of ruptured and unruptured symptomatic posterio inferior cerebellar artery aneurysms. Br J Neurosurg. 2004; I8:608-6I2.

4I. Salcman M, Rigamonti D, Numaguchi Y, Sadato N. Aneurysms of the posterior inferior cerebellar artery-vertebral artery complex: variations on a theme. Neurosurgery. I990;27:I2-20 [discussion: 2O-2I]

42. Yamaura A, Isobe K, Karasudani H, Tanaka M, Komiya H. Dissecting aneurysms of the posterior inferior cerebellar artery. Neurosurgery. I99I;28: $894-898$.

43. Seoane P, Kalb S, Clark JC, Rivas JC, Xu DS, Mendes GA, et al. Far-lateral approach without drilling the occipital condyle for vertebral arteryposterior inferior cerebellar artery aneurysms. Neurosurgery. 2017;8I:268-274.

44. Lehto H. Aneurysms of the Vertebral and Posterior Inferior Cerebellar Arteries. Helsinki: University of Helsinki; 2015.

45. Randell T, Niemela M, Kytta J, Tanskanen P, Maattanen M, Karatas A, et al. Principles of neuroanesthesia in aneurysmal subarachnoid hemorrhage: the Helsinki experience. Surg Neurol. 2006 66:382-388 [discussion: 388 ].

46. Batjer H, Samson D. Intraoperative aneurysmal rupture: incidence, outcome, and suggestions for surgical management. Neurosurgery. I986;18: 70I-707.

47. Lawton MT, Du R. Effect of the neurosurgeon's surgical experience on outcomes from intraoperative aneurysmal rupture. Neurosurgery. 2005; 57:9-I5 [discussion: 9-I5].

48. Leipzig TJ, Morgan J, Horner TG, Payner T, Redelman K, Johnson CS. Analysis of intraoperative rupture in the surgical treatment of 1694 saccular aneurysms. Neurosurgery. 2005;56:455-468 [discussion: 455-468]. 
49. Sandalcioglu IE, Schoch B, Regel JP, Wanke I, Gasser T, Forsting M, et al. Does intraoperative aneurysm rupture influence outcome? Analysis of I69 patients. Clin Neurol Neurosurg. 2004;I06:88-92.

50. Chen SF, Kato Y, Kumar A, Tan GW, Oguri D, Oda J, et al. Intraoperative rupture in the surgical treatment of patients with intracranial aneurysms. J Clin Neurosci. 2016;34:63-69.

5I. Araki Y, Andoh H, Yamada M, Nakatani K, Andoh T, Sakai N. Permissible arterial occlusion time in aneurysm surgery: postoperative hyperperfusion caused by temporary clipping. Neurol Med Chir (Tokyo). I999;39:90I-906 [discussion: 906-907].

52. Dhandapani S, Pal SS, Gupta SK, Mohindra S, Chhabra R, Malhotra SK. Does the impact of elective temporary clipping on intraoperative rupture really influence neurological outcome after surgery for ruptured anterior circulation aneurysms? A prospective multivariate study. Acta Neurochir (Wien). 20I3;155:237-246.

53. Ogilvy CS, Carter BS, Kaplan S, Rich C, Crowell RM. Temporary vessel occlusion for aneurysm surgery: risk factors for stroke in patients protected by induced hypothermia and hypertension and intravenous mannitol administration. J Neurosurg. I996;84:785-79I.

54. Samson D, Batjer HH, Bowman G, Mootz L, Krippner WJ Jr, Meyer YJ, et al. A clinical study of the parameters and effects of temporary arterial occlusion in the management of intracranial aneurysms. Neurosurgery. I994;34:22-28 [discussion: 28-29].

55. Schick U, Dohnert J, Meyer J, Vitzthum HE. Effects of temporary clips on somatosensory evoked potentials in aneurysm surgery. Neurocrit Care. 2005;2:I4I-I49.

56. Eftekhar B, Morgan MK. Indications for the use of temporary arterial occlusion during aneurysm repair: an institutional experience. J Clin Neurosci. 20II;I8:905-909.
57. Al-khayat H, Al-Khayat H, Beshay J, Manner D White J. Vertebral artery-posteroinferior cerebellar artery aneurysms: clinical and lower cranial nerve outcomes in 52 patients. Neurosurgery. 2005;56:2-10 [discussion: $\mathrm{II}$ ].

58. Chalouhi N, Jabbour P, Starke RM, Tjoumakaris SI, Gonzalez LF, Witte S, et al. Endovascular treatment of proximal and distal posterior inferior cerebellar artery aneurysms. J Neurosurg. 2013;118:99I-999.

59. Mericle RA, Reig AS, Burry MV, Eskioglu E, Firment CS, Santra S. Endovascular surgery for proximal posterior inferior cerebellar artery aneurysms: an analysis of Glasgow Outcome Score by Hunt-Hess grades. Neurosurgery. 2006;58: 619-625 [discussion: 619-625].

6o. Peluso JP, van Rooij WJ, Sluzewski M, Beute GN, Majoie CB. Posterior inferior cerebellar artery aneurysms: incidence, clinical presentation, and outcome of endovascular treatment. AJNR Am J Neuroradiol. 2008;29:86-90.

6I. Madaelil TP, Wallace AN, Chatterjee AN, Zipfel GJ, Dacey RG Jr, Cross DT 3rd, et al. Endovascular parent vessel sacrifice in ruptured dissecting vertebral and posterior inferior cerebellar artery aneurysms: clinical outcomes and review of the literature. J Neurointerv Surg. 2016;8:796-80I.

62. Satow T, Ishii D, Iihara K, Sakai N, Group JNS Endovascular treatment for ruptured vertebral artery dissecting aneurysms: results from Japanese Registry of Neuroendovascular Therapy (JR-NET I and 2. Neurol Med Chir (Tokyo). 2014;54:98-1o6.

63. Urasyanandana K, Withayasuk P, Songsaeng D, Aurboonyawat T, Chankaew E, Churojana A. Ruptured intracranial vertebral artery dissecting aneurysms: an evaluation of prognostic factors of treatment outcome. Interv Neuroradiol. 2017;23: 240-248.

64. Xu F, Hong Y, Zheng Y, Xu Q, Leng B. Endovascular treatment of posterior inferior cerebellar artery aneurysms: a 7-year single-center experience. J Neurointerv Surg. 20I7;9:45-5I.

65. Mukonoweshuro W, Laitt RD, Hughes DG. Endovascular treatment of PICA aneurysms. Neuroradiology. 2003;45:I88-I92.

66. Bradac GB, Bergui M. Endovascular treatment of the posterior inferior cerebellar artery aneurysms. Neuroradiology. 2004;46:1006-IoII.

67. Crowley RW, Albuquerque FC, Ducruet AF, Williamson RW, McDougall CG. Technical considerations in the endovascular management of aneurysms of the posterior inferior cerebellar artery. Neurosurgery. 20I2;7I(2 suppl operative): ons204-ons2I7 [discussion: ons2I7-ons2I8].

68. Juszkat R, Kram P, Stanislawska K, Jankowski R, Stachowska-Tomczak B, Nowak S, et al. Ten year of experience in endovascular treatment of ruptured aneurysms of the posterior inferior cerebellar artery. Interv Neuroradiol. 20I6;22: I29-I37.

69. Bohnstedt BN, Ziemba-Davis M, Edwards G, Brom J, Payner TD, Leipzig TJ, et al. Treatment and outcomes among I02 posterior inferior cerebellar artery aneurysms: a comparison of endovascular and microsurgical clip ligation. World Neurosurg. 2015;83:784-793.

Conflict of interest statement: The authors declare that the article content was composed in the absence of any commercial or financial relationships that could be construed as a potential conflict of interest

Received 12 July 2017; accepted 2 September 2017

Citation: World Neurosurg. (2017) 108:336-346.

https://doi.org/10.1016/j.wneu.2017.09.014

Journal homepage: www.WORLDNEUROSURGERY.org

Available online: www.sciencedirect.com

1878-8750/\$ - see front matter (C) 2017 Elsevier Inc. All rights reserved. 